\title{
3D metallic glass cellular structures
}

Ze Liu $^{\mathrm{a}, \mathrm{b}, \mathrm{c}, \dagger}$, Wen Chen ${ }^{\mathrm{a}, *}$, Josephine Carstensen ${ }^{\mathrm{d}}$, Jittisa Ketkaew ${ }^{\mathrm{a}}$, Rodrigo Miguel Ojeda

$$
\text { Mota }^{\text {a }} \text {, James K. Guest }{ }^{\text {d }} \text {, Jan Schroers }{ }^{\text {a, b }}
$$

${ }^{a}$ Department of Mechanical Engineering \& Materials Science, Yale University, New Haven,

$$
\text { CT, 06511, USA }
$$

${ }^{\mathrm{b}}$ Center for Research on Interface Structures and Phenomena (CRISP), Yale University

${ }^{c}$ Department of Engineering mechanics, School of Civil Engineering, Wuhan University, Wuhan, China

${ }^{\mathrm{d}}$ Department of Civil Engineering, Johns Hopkins University, Baltimore, MD, 21218, USA Corresponding Authors: ${ }^{\dagger}$ ze.liu@yale.edu or ze.liu@live.com; *chen.wen@yale.edu

\begin{abstract}
3D Metallic glass structures (3DMGs) are fabricated through thermoplastic forming (TPF)-based patterning of MG sheets combined with a parallel joining technique. To demonstrate this capability and benchmark 3DMGs, we have fabricated honeycomb-like MG architectures covering a wide range of relative densities. 3DMGs exhibit high elasticity of up to $40 \%$ loading strain, high elastic energy storability, and high energy absorption which is superior compared to those made from other materials such as conventional metals and ceramics, based on our theoretical analysis. The combination of $\mathrm{MG}$ properties and introduced versatile fabrication method suggest the possibility of developing a wide range of 3DMGs with excellent performance for specific applications.
\end{abstract}

Keywords: Metallic glass; Cellular structure; Thermoplastic forming; Mechanical behavior; energy absorption 


\section{Introduction}

Microstructural architectures with material specific design have been proven powerful in nature and engineering applications. Natural materials, such as shells [1-3], tooth [4, 5], or bone $[6,7]$, exhibit complex hierarchical structures spanning from microscopic to macroscopic length scales [8] and show significantly improved mechanical properties (e.g. strength and toughness) compared to base materials [9, 10]. Applications of engineering materials with synthetic structures range broadly, from advanced aerospace structures [11, 12], structural foams [13-15], multifunctional micro-lattices [16-18], and topology-optimized architectures [16, 19-22] to bio-inspired architectures [23, 24]. Taking cellular metals for example, the high specific strengths and large compressibility makes them powerful for energy-absorbing applications. In general, energy absorption of a cellular material scales directly with its strength and plasticity. Bulk metallic glasses (BMGs) are a class of amorphous metals that possess very high strength. They are often not plastic in bulk forms $(>1 \mathrm{~mm})$ but can be very plastic at small scales $(<1 \mathrm{~mm})$ [25-27]. In addition, the significantly higher elasticity of BMGs $(\sim 2 \%)$ over crystal metals $(\sim 0.8 \%)$ or ceramics $(\sim$ $0.2 \%)$ offers a high possibility to develop super-elastic "spring-like" cellular structures. The length scale effect has been widely utilized in BMG stochastic foams [28-34]. It has also inspired development of materials with architectural features scaled to the BMGs' critical crack length. By introducing isolated dendrites, spaced by tens of microns in a metallic glass matrix, toughness and ductility of the BMG composites are drastically increased $[35,36]$. Through bio-inspired hierarchical arrangements of different structural elements at length scales spanning from nanometers to micrometers, Ti-N nanolattices with very high strength 
(up to $1.75 \mathrm{GPa}$ ) [37] and alumina nanolattices exhibiting very high elasticity (fully recoverable with strain up to 50\%) [38] were fabricated by using a template-assisted electroless plating method [39].

Microstructural architectures are either periodic or stochastic. Stochastic architectures contain random distributions of heterogeneities. In the case of stochastic foams, which have been widely explored for BMGs [28-34], gas is incoorporated during processing and the resulting porous BMGs tend to contain uneven bubble (pore) size distributions throughout the resulting architectures. Although foams can generally be manufactured at low costs, the randomness of the underlying architectures leads to a significant reduction in material performance [40, 41]. Periodic architectures, on the other hand, feature ordered heterogeneities that may be engineered to optimally tailor material performance. Classic examples include microtruss lattice $[17,19,40,41]$ and topology-optimized architectures [24, 25]. The drawback of these architectures is that they are generally more difficult to manufacture than stochastic materials, particularly in the case of three-dimensionally architected BMGs, which have thus far not been accomplished successfully. Using the artificial microstructure strategy based on replicating silicon molds with BMGs, 2D cellular BMGs have been fabricated and characterized [36, 42-44]. The precision and versatility of this method has enabled the study of fundamental aspects of cellular BMGs [36, 42-44]. However this method is not extendable to the fabrication of 3D structures as microfabrication is a planar process. Recently, 3D printing [45] has offered a novel approach to designing and manufacturing three-dimensional complex parts from polymers, metals, and ceramics. 
Examples have included stretch-dominated ultra-stiff microlattices [46], and cellular architectures with negative stiffness [47] and negative Poisson's ratio [48]. The application of 3D printing to fabricate BMG cellular structures was recently achieved by using selective laser melting [49]. However, reducing microvoids during the melting of BMG powders and preventing crack formation during solidification are major challenges to this approach.

Here, we introduce a fabrication method that allows us to precisely fabricate BMG structures with desirable architectures and scalable size in 3D. Our method is based on thermoplastic forming (TPF)-based patterning of BMG sheets combined with a parallel joining technique. To demonstrate this capability, we have fabricated honeycomb-like BMG architectures covering a wide range of relative densities. These structures exhibit very high elasticity of up to $40 \%$ loading strain, high elastic energy storability, and high energy absorption.

\section{Fabrication of 3D BMG Material Architectures}

\subsection{BMG sheets through thermoplastic rolling}

The proposed procedure for fabricating 3D BMG cellular architectures consists of four primary steps (Fig. 1): (1) formation of BMG sheets, (2) TPF-based patterning and perforation of BMG sheets, (3) parallel joining, and (4) demoulding. The starting material used in our fabrication experiments is cast $\mathrm{Zr}_{35} \mathrm{Ti}_{30} \mathrm{Cu}_{8.25} \mathrm{Be}_{26.75}$ rods, which is a highly reactive, low-cost, and readily accessible metallic glass. These rods have a diameter of 10

$\mathrm{mm}$ and length of $10 \mathrm{~cm}$, and a glass transition temperature of $T_{\mathrm{g}}=305{ }^{\circ} \mathrm{C}$ and a crystallization onset temperature of $T_{\mathrm{x}}=464{ }^{\circ} \mathrm{C}$. 
The as-cast BMG rods were manufactured into BMG sheets by first thermoplastically compressing the rods with $50 \mathrm{KN}$ at $430{ }^{\circ} \mathrm{C}$ by using an Instron universal testing machine equipped with a precisely controlled heating cell. The pre-pressed sample was subsequently thermoplastically rolled by using a home-built hot-rolling machine. The typical preheating and rolling temperatures were separately controlled and set at $400{ }^{\circ} \mathrm{C}$ and $420{ }^{\circ} \mathrm{C}$, respectively, and the applied rolling speed is $150 \mathrm{~mm} / \mathrm{min}$. After several passes, a typical BMG sheet with a diameter of $\sim 15 \mathrm{~cm}$ and a thickness of $\sim 0.4 \mathrm{~mm}$ was obtained (Fig. 1a).

\subsection{D BMG structures by thermoplastic joining in air}

The large BMG sheets were subsequently thermoplastically patterned into corrugated brass molds at $400{ }^{\circ} \mathrm{C}$ (Fig. 1b). These molds allow for creating hierarchical structures such as through-holes with an additional design tool. The corrugated BMG sheets were then arranged and assembled by metal supports into the designed 3D structures. A parallel joining process was employed to join the selectively contacted interfaces (Fig. 1c). The joining process (Temperature of $430{ }^{\circ} \mathrm{C}$ ) relies on the thermoplastic straining of the BMG interface and the main advantage of our fabrication is that it can be all carried out in air environment. Our motivation is to develop a joining technique which can be practically utilized and as one aspect it can be performed without vacuum or protective atmosphere. We have successfully developed such a thermoplastic straining based joining approach that is highly effective even for very active metallic glass alloys such as Zr-based ones. The detailed mechanism and numerical analysis of this joining process has been explained in our previous work [50]. Mechanistically, the oxide layer is typically $<1 \mu \mathrm{m}$ thick (Fig. 2) [51] and during straining of 
the interface, the membrane tensile stress within the oxide layer under the lateral flow is significantly higher than the fracture strength of the oxide. Hence, the oxide breaks and pristine alloy flows towards the interface and forms a metallic bond. Since the joined area fraction at the interface scales linearly with the applied thermoplastic strain, we can therefore join metallic glasses in a highly predictable manner that the resultant shear strength of the joint is directly proportional to the applied thermoplastic strain at the interface and the parent material's shear strength. The ability to join even reactive metallic glasses in air on a timescale of the order of milliseconds to seconds at a low thermoplastic flow pressure with predictable joint strength suggests that our approach is a highly practical and economic method to join metallic glasses. Before the development of this joining approach, 3D BMG cellular structures has being very challenging to accomplish.

Fabrication of a typical 3D BMG honeycomb-like architecture was completed after parallel joining and subsequent removal of the metal support (Fig. 1d-f). The use of highly reactive, low-cost, and readily accessible $\mathrm{Zr}$-Ti-Cu-Be metallic glass to fabricate cellular structures can not only help prove the high effectiveness of the joining method, but also demonstrate a high technical practicability for the structural application of metallic glasses. Comparison of our BMG structures fabrication method to other fabrication methods revealed that scalability and practicality are the major advantages of our fabrication process (Tab. 1).

\subsection{Structural evolution during thermoplastic forming}

Metallic glasses are metastable and structural relaxation or crystallization can affect the 
mechanical properties [52]. Therefore, before TPF of metallic glasses, TPF time window was firstly measured by isothermal tests using Differential Scanning Calorimetry (DSC), and we thermoplastically processed metallic glasses within such a time window to avoid crystallization. After TPF, structural characterization was carried out through both X-ray diffraction (XRD) and DSC. Our results confirmed that the material preserves its amorphous nature after TPF (Fig. 3). We also characterized the mechanical property evolution by beam bending using a home-built bending mandrel. Bending has been proven as a very sensitive and hence effective measure to characterize the mechanical performance of metallic glasses [53]. We have measured almost the same bending plasticity of $\sim 5 \%$ before and after thermoplastic processing.

\section{Mechanical Testing and Characterization}

\subsection{Experimental Procedure}

The fabricated 3D cellular architectures made from $\mathrm{Zr}_{35} \mathrm{Ti}_{30} \mathrm{Cu}_{8.25} \mathrm{Be}_{26.75}$ were quasi-statically compressed using an Instron universal testing machine with flat and parallel heads. All samples were loaded with an initial strain rate of $1.0 \times 10^{-3} \mathrm{~s}^{-1}$. For cyclic loading, the unloading rate was one order of magnitude larger than the loading rate.

\subsection{Experimental Results}

A typical stress-strain curve associated with the corresponding microstructural evolution (selected from an in situ movie, see Supplementary section) is shown in Fig. 4 for a 3D BMG honeycomb-like architecture with a relative density of $\rho / \rho_{\mathrm{s}}=0.073$, where $\rho$ is the apparent density of cellular structure and $\rho_{\mathrm{s}}$ is the density of the base material for the cellular structure. 
A wide variety of deformation behaviors including elastic deformation ( 15\%), plastic yielding, and densification were observed. The long plateau region from $\sim 15 \%$ to $\sim 80 \%$ was enhanced through plastic deformation. This high plasticity indicates the remarkable energy absorption properties of the 3D BMG cellular structures [54-58]. After unloading, the 3D BMG structure was partially recovered and the joined interfaces remained intact without failure through delamination (9), inset of Fig. 4). Similar behaviors were observed for another three cellular structures but with different relative densities (Fig. 9a), the larger of $\rho$, the higher of yielding strength but the lower of elasticity, which is understandable since $\frac{\rho}{\rho_{s}}=\frac{2}{\sqrt{3}} \frac{h}{l} \propto \frac{h}{l}$ (for honeycomb cellular structures), where $h$ and $l$ are the thickness and length of cell wall respectively. Therefore, a larger aspect ratio of cell walls leads to a smaller relative density and an easier transformation from linear elasticity to non-linear elasticity (or elastic buckling).

The tested samples were further characterized by SEM. A typical unit cell after compression up to $90 \%$ strain is shown in Fig. 5a-c. Severe deformation localization is observed near the roots of the cell wall beam segments (A and B in Fig. 5a-c). These are the locations of the largest bending moments and consequently largest bending stresses, and thus the location of this localization is not surprising. However, it is clear from these images that delamination at the joint was not observed, suggesting the bond was sufficiently strong to resist any present shear stresses. In order to further investigate the joint interface, a joint was intentionally broken and imaged. As can be seen in Fig. 5d and 5e, the appearance of vein-patterns on both 
of the separated surfaces suggests the formation of metallurgical bonds in these joined regions.

In addition to the substantially enhanced macroscopic plasticity (Fig. 4), super-elasticity was also observed in the 3DMGs during the quasi-static cyclic loading test. Two load cycles are shown in Fig. 6 for a typical 3D honeycomb-like BMG structure with $\rho / \rho_{\mathrm{s}}=0.031$, which we note is below the critical density $(\sim 5 \%)$ for elastic buckling $[43,59]$. The results show that the structure can fully recover under an applied strain of $\sim 35 \%$, exhibiting a very high observed elasticity. After further loading to $40 \%$ strain in the second cycle, the residual strain after unloading is below 2\% (Fig. 6).

\subsection{Analytical Approximation to Elasticity and Stored Elastic Energy}

To compare the elasticity and elastic energy storability of 3D honeycomb-like architectures made from BMGs with those made from other materials, a simplified analytical model is used to approximate the behavior. The elastic deformation of such a unit cell is mainly from the side walls, which are bending-dominated for high aspect ratios. Denoting the wall length as $L$ and wall thickness $h$, and employing symmetry of the structure as shown in Fig. 7, the resulting deflection of the bending beam can be approximated as

$$
y^{\prime}=\frac{\delta}{2}\left(1-\cos \left(\frac{\pi}{L^{\prime}} x^{\prime}\right)\right)
$$

and the maximum curvature is

$$
k_{\max }=\frac{\pi^{2} \delta}{2 L^{\prime 2}}
$$


The onset of plastic yielding occurs when

$$
k_{\max }=\frac{2 \varepsilon_{\mathrm{cr}}}{h}
$$

where $\varepsilon_{\text {cr }}$ is the elastic limit of the beam base material. Combining Eqs. (2) and (3) gives

$$
\delta=\frac{4 \varepsilon_{\mathrm{cr}} L^{\prime 2}}{\pi^{2} h}
$$

For bending dominated deformation, we neglect the length variation of the beam and we have

$$
\frac{1}{\lambda}=\int_{0}^{1} \sqrt{1+\frac{4 \varepsilon_{\mathrm{cr}}^{2}}{\pi^{2}}\left(\frac{L}{h}\right)^{2} \lambda^{2} \sin ^{2}\left(\pi x^{\prime}\right)} d x^{\prime}
$$

where $\lambda=L^{\prime} / L$, and the maximum elastic strain is thus

$$
\varepsilon_{\text {ap }, \max }=1-\lambda+\frac{4 \varepsilon_{\mathrm{cr}}}{\pi^{2}} \frac{L}{h} \lambda^{2} \tan \theta
$$

where $\theta$ is the angle between side wall and the loading direction. Eq. (6) suggests that the maximum elasticity of $3 \mathrm{D}$ honeycomb-like structures is a function of specific material properties $\left(\varepsilon_{\mathrm{cr}}\right)$, aspect ratio $(L / h)$, and tilt angle of the side beams $(\theta)$. The corresponding stress $\left(\sigma_{0}\right)$ at the maximum elastic strain is

$$
\sigma_{0}=\frac{\pi^{2} E \varepsilon_{\mathrm{cr}} \cos \theta}{3(1+\sin \theta)}\left(\frac{h}{L}\right)^{3} \frac{1}{4 \lambda \varepsilon_{\mathrm{cr}}+\frac{\pi^{2}}{2} \frac{h}{L}\left(1-\varepsilon_{\mathrm{ap}, \max }\right) \sin (2 \theta)}
$$

where $E$ is the Young's modulus of the beam base material. On the other hand, the Young's modulus of the structure is given by [59]

$$
E^{*}=E\left(\frac{h}{L}\right)^{3} \frac{\cos \theta}{(1+\sin \theta) \sin ^{2} \theta}
$$

Using Eqs. (6-8), we can estimate the maximum elastic strain energy stored by the structure by (inset of Fig. 8b)

$$
U_{\mathrm{el}} \approx \sigma_{0} \varepsilon_{\mathrm{ap}, \max }-\frac{\sigma_{0}^{2}}{2 E^{*}}
$$


Fig. 8 shows the maximum elasticity and the corresponding stored elastic strain energy, estimated using Eq. (6) and Eq. (9), for a regular honeycomb structure where $\theta=30^{\circ}$. Typical material properties for the material types are assumed $\left(\varepsilon_{\mathrm{cr}}=0.2 \%, E=300 \mathrm{GPa}\right.$ for ceramics, $\varepsilon_{\mathrm{cr}}=0.8 \%, E=200 \mathrm{GPa}$ for metals, and $\varepsilon_{\mathrm{cr}}=2 \%, E=100 \mathrm{GPa}$ for BMGs). Our estimates reveal that the elasticity and the elastic energy storability of BMG honeycomb structures are superior to those made from metals or ceramics at any given density (Fig. 8). For comparison, our experimental results for 3D honeycomb-like structures made from $\mathrm{Zr}_{35} \mathrm{Ti}_{30} \mathrm{Cu}_{8.25} \mathrm{Be}_{26.75}$ are shown, in good agreement with the analytical predictions.

\section{Finite Element Analysis (FEA) of Honeycomb-like BMG Architectures}

In order to examine the failure mechanism of the BMG honeycomb-like architectures, finite element analysis (FEA) was performed on an idealized BMG honeycomb model. The BMG base material was assumed to exhibit elastic perfectly plastic constitutive behavior [60], with mechanical parameters for $\mathrm{Zr}_{35} \mathrm{Ti}_{30} \mathrm{Cu}_{8.25} \mathrm{Be}_{26.75}$ taken as Young's modulus $E=86.9 \mathrm{GPa}$, Poisson's ratio $v=0.37$, and yield strength $\sigma_{\mathrm{s}}=1.43 \mathrm{GPa}$, respectively [61]. The analyzed structures consisted of four horizontal and three vertical layers of hexagonal honeycombs, assumed to be perfectly regular (no imperfections). The cell wall length $L$ and thickness $h$ were estimated from the fabricated specimens and are shown in Tab. 2. Note that the mean thickness across the cell wall was taken for $h$, and thickness variation or other geometrical imperfections were not considered. The bonded joints at the folded BMG sheet interfaces were assumed perfect such that the structure is essentially monolithic. These simplifications were made to facilitate comparison to the analytical analysis of hexagonal honeycomb 
behavior as described in Reference [59].

The analyses were conducted in the commercial FEA code ABAQUS 6.13. The architectures were meshed using 2D plane strain using bilinear quadrilateral elements with hourglass control CPE4R. The top and bottom boundaries of the samples were assumed frictionless, and therefore only vertical deflections were restrained with a single node having horizontal deflection restrained for kinematic stability. The samples were loaded by imposing a downward vertical displacement uniformly on the top boundaries of the samples with a deformation load step of maximum $0.015 \mathrm{~mm}$. Geometric nonlinearities were considered, and a perfect elastic-plastic model was assumed until an ultimate strain of $25 \%$, beyond which a rapidly linearly decreasing softening model was defined to simulate failure of the BMG. Classic metal plasticity was assumed for the material definition using Mises's Yield surface, isotropic hardening and an associated flow rule. The models were analyzed using Riks method as the arc length analysis method and contact was not considered. The stopping criterion of the analyses was therefore initiation of unit cell collapse.

The stress-strain response curves for the four different relative densities $\left(\rho / \rho_{\mathrm{s}}\right), 0.06,0.07$, 0.09 and 0.11, are shown in Fig. 9a with the FEA simulation shown as solid-lines and the experimental results as dot-dashed lines. It is obvious that the mechanical responses of the structures from FEA set the upper bounds for our experiments. This is to be expected as the fabricated specimens contain geometric imperfections and thickness variations, which were not captured in the FEA model. Similar behavior was reported previously for aluminum 
cellular foams [62-64]. However, for the same relative density, 3D BMG structures are superior compared to aluminum foams (Fig. 9b)

Consistent with the prediction by theoretical analysis, the numerical models suggest different deformation mechanisms for 3DMGs with different relative densities, for example, buckling-dominated mechanism for $\rho / \rho_{\mathrm{s}}=0.06,0.07$, and 0.09 and plastic yielding-dominated mechanism for $\rho / \rho_{\mathrm{s}}=0.11$. Fig. 10 illustrates these failure modes. For $\rho / \rho_{\mathrm{s}}=0.06$ (Fig. 10a), the cell walls deform in a s-shape manner, which is clearly indicative of buckling, while Fig. $10 \mathrm{~b}, 10 \mathrm{e}$ show significant regions of yielded material around the joints without evidence of buckling for $\rho / \rho_{\mathrm{s}}=0.11$. The finite element mesh is quite refined, as shown in Figure 10c, and the numerically estimated behavior does not change with mesh refinement. Although the failure mechanisms are consistent with the analytical models, the numerical models estimate a slightly lower elastic stiffness of approximately $8-26 \%$ and lower strength of approximately $14-36 \%$ than the theoretical model using the same relative densities. This is likely due to the fact that the theoretical expressions assume infinite periodicity while the FE models exhibit finite periodicity for the purpose of comparison to experiments.

It should be noted that the FE and analytical models assume perfect geometry and uniform wall thickness, while the fabricated samples exhibited minor imperfections in geometry and fairly large variations in member thickness of $\sim 20 \%$, to which we attribute the deviation between FEA and experimental results (Fig. 9). Interestingly, the thickness in the members is typically largest where the slanted columns and the horizontal beams meet due to the joining 
process, which is also the location of maximum stress predicted by the idealized FE models (Fig. 10), and thinnest near midspan of the members. These effects together may transition the architecture from plastic yielding to buckling-dominated failure mode for low relative densities. A numerical model with imperfections in the wall thickness was made of the high-density sample with $\rho / \rho_{\mathrm{s}}=0.11$. The thickness in this model was random and uncorrelated with a standard deviation of $20 \%$. The resulting stiffness and the strength were reduced by $20 \%$ and $19 \%$, respectively, compared to the numerical sample with uniform wall thickness, and the failure mechanism was still found to be plastic yielding dominated. Considering the size effect on the behavior of this isolated type of imperfection, being able to characterize the thickness variation is considered important in achieving accurate estimations of the BMG structural behavior, and is the subject of future work.

\section{Summary}

In summary, we have fabricated 3D BMG cellular structures. The developed fabrication method is based on thermoplastic forming and parallel joining. The versatility and practicability of our method allows fabrication of scalable and highly controllable 3D metallic glass structures (Tab. 1). Besides the previously observed drastically enhanced macroscopic plasticity, which is a requisite for energy adsorption, super-elasticity of 3D BMG honeycomb-like structures has been observed. For some densities, deformation is almost fully recoverable up to a maximum loading strain of $40 \%$. The super-elasticity combined with high strength in our 3D honeycomb-like structures endow them with excellent elastic energy storability, superior compared to those made from other materials such as metals and ceramics. The combination of BMG properties and the developed versatile 
fabrication method suggest the possibility of developing a wide range of BMG structures with excellent performance for specific applications.

\section{Acknowledgements}

This work was primarily supported by DARPA through the MCMA program. Facilities use was supported by CRISP through the National Science Foundation under MRSEC DMR-1119826.

\section{References:}

[1] J.D. Currey. Mechanical-Properties of Mother of Pearl in Tension, Proc R Soc Ser B-Bio 196 (1977) 443-463.

[2] R. Menig, M.H. Meyers, M.A. Meyers, K.S. Vecchio. Quasi-static and dynamic mechanical response of Haliotis rufescens (abalone) shells, Acta Materialia 48 (2000) 2383-2398.

[3] S. Kamat, X. Su, R. Ballarini, A.H. Heuer. Structural basis for the fracture toughness of the shell of the conch Strombus gigas, Nature 405 (2000) 1036-1040.

[4] W. Tesch, N. Eidelman, P. Roschger, F. Goldenberg, K. Klaushofer, P. Fratzl. Graded microstructure and mechanical properties of human crown dentin, Calcified Tissue Int 69 (2001) 147-157.

[5] S. Weiner, A. Veis, E. Beniash, T. Arad, J.W. Dillon, B. Sabsay, F. Siddiqui. Peritubular dentin formation: Crystal organization and the macromolecular constituents in human teeth, J Struct Biol 126 (1999) 27-41.

[6] W.J. Landis. The Strength of a Calcified Tissue Depends in Part on the Molecular-Structure and Organization of Its Constituent Mineral Crystals in Their Organic Matrix, Bone 16 (1995) 533-544.

[7] P. Fratzl, H.S. Gupta, E.P. Paschalis, P. Roschger. Structure and mechanical quality of the collagen-mineral 
nano-composite in bone, J Mater Chem 14 (2004) 2115-2123.

[8] P. Fratzl, R. Weinkamer. Nature's hierarchical materials, Prog Mater Sci 52 (2007) 1263-1334.

[9] H.J. Gao, B.H. Ji, I.L. Jager, E. Arzt, P. Fratzl. Materials become insensitive to flaws at nanoscale: Lessons from nature, P Natl Acad Sci USA 100 (2003) 5597-5600.

[10] M.A. Meyers, P.Y. Chen, A.Y.M. Lin, Y. Seki. Biological materials: Structure and mechanical properties, Prog Mater Sci 53 (2008) 1-206.

[11] L.B. Vogelesang, A. Vlot. Development of fibre metal laminates for advanced aerospace structures, J Mater Process Tech 103 (2000) 1-5.

[12] G.C. Wu, J.M. Yang. The mechanical behavior of GLARE laminates for aircraft structures, Jom-Us 57 (2005) 72-79.

[13] C.D. Han, H.J. Yoo. Studies on Structural Foam Processing .4. Bubble-Growth during Mold Filling, Polym Eng Sci 21 (1981) 518-533.

[14] K. Boomsma, D. Poulikakos. On the effective thermal conductivity of a three-dimensionally structured fluid-saturated metal foam, Int J Heat Mass Tran 44 (2001) 827-836.

[15] J. Banhart. Manufacture, characterisation and application of cellular metals and metal foams, Prog Mater Sci 46 (2001) 559-U553.

[16] H.N.G. Wadley. Multifunctional periodic cellular metals, Philos T Roy Soc A 364 (2006) 31-68.

[17] A. Torrents, T.A. Schaedler, A.J. Jacobsen, W.B. Carter, L. Valdevit. Characterization of nickel-based microlattice materials with structural hierarchy from the nanometer to the millimeter scale, Acta Materialia 60 (2012) 3511-3523.

[18] L.Y. Zhao, S. Ha, K.W. Sharp, A.B. Geltmacher, R.W. Fonda, A.H. Kinsey, Y. Zhang, S.M. Ryan, D. Erdeniz, D.C. Dunand, K.J. Hemker, J.K. Guest, T.P. Weihs. Permeability measurements and modeling of 
topology-optimized metallic 3-D woven lattices, Acta Materialia 81 (2014) 326-336.

[19] O. Sigmund, S. Torquato. Design of materials with extreme thermal expansion using a three-phase topology optimization method, J Mech Phys Solids 45 (1997) 1037-1067.

[20] J.K. Guest, J.H. Prevost. Optimizing multifunctional materials: Design of microstructures for maximized stiffness and fluid permeability, Int J Solids Struct 43 (2006) 7028-7047.

[21] V.J. Challis, J.K. Guest, J.F. Grotowski, A.P. Roberts. Computationally generated cross-property bounds for stiffness and fluid permeability using topology optimization, Int J Solids Struct 49 (2012) 3397-3408.

[22] J. Cadman, S. Zhou, Y. Chen, Q. Li. On design of multi-functional microstructural materials, J Mater Sci 48 (2013) 51-56.

[23] P. Greil, T. Lifka, A. Kaindl. Biomorphic cellular silicon carbide ceramics from wood: I. Processing and microstructure, J Eur Ceram Soc 18 (1998) 1961-1973.

[24] E. Munch, M.E. Launey, D.H. Alsem, E. Saiz, A.P. Tomsia, R.O. Ritchie. Tough, Bio-Inspired Hybrid Materials, Science 322 (2008) 1516-1520.

[25] R.D. Conner, W.L. Johnson, N.E. Paton, W.D. Nix. Shear bands and cracking of metallic glass plates in bending, Journal of Applied Physics 94 (2003) 904-911.

[26] H. Guo, P.F. Yan, Y.B. Wang, J. Tan, Z.F. Zhang, M.L. Sui, E. Ma. Tensile ductility and necking of metallic glass, Nature materials 6 (2007) 735-739.

[27] J.R. Greer, J.T.M. De Hosson. Plasticity in small-sized metallic systems: Intrinsic versus extrinsic size effect, Prog Mater Sci 56 (2011) 654-724.

[28] J. Schroers, C. Veazey, W.L. Johnson. Amorphous metallic foam, Applied Physics Letters 82 (2003) $370-372$.

[29] T. Wada, A. Inoue. Fabrication, thermal stability and mechanical properties of porous bulk glassy 
Pd-Cu-Ni-P alloys, Mater Trans 44 (2003) 2228-2231.

[30] A.H. Brothers, R. Scheunemann, J.D. DeFouw, D.C. Dunand. Processing and structure of open-celled amorphous metal foams, Scripta Materialia 52 (2005) 335-339.

[31] M.H. Lee, D.J. Sordelet. Synthesis of bulk metallic glass foam by powder extrusion with a fugitive second phase, Applied Physics Letters 89 (2006) 021921.

[32] A.H. Brothers, D.C. Dunand. Syntactic bulk metallic glass foam, Applied Physics Letters 84 (2004) 1108-1110.

[33] J. Jayaraj, B.J. Park, D.H. Kim, W.T. Kim, E. Fleury. Nanometer-sized porous Ti-based metallic glass, Scripta Materialia 55 (2006) 1063-1066.

[34] J. Schroers, C. Veazey, M.D. Demetriou, W.L. Johnson. Synthesis method for amorphous metallic foam, Journal of Applied Physics 96 (2004) 7723-7730.

[35] D.C. Hofmann, J.Y. Suh, A. Wiest, G. Duan, M.L. Lind, M.D. Demetriou, W.L. Johnson. Designing metallic glass matrix composites with high toughness and tensile ductility, Nature 451 (2008) 1085-U1083.

[36] B. Sarac, J. Schroers. Designing tensile ductility in metallic glasses, Nat Commun 4 (2013) 1-7.

[37] D.C. Jang, L.R. Meza, F. Greer, J.R. Greer. Fabrication and deformation of three-dimensional hollow ceramic nanostructures, Nature materials 12 (2013) 893-898.

[38] L.R. Meza, S. Das, J.R. Greer. Strong, lightweight, and recoverable three-dimensional ceramic nanolattices, Science 345 (2014) 1322-1326.

[39] T.A. Schaedler, A.J. Jacobsen, A. Torrents, A.E. Sorensen, J. Lian, J.R. Greer, L. Valdevit, W.B. Carter. Ultralight Metallic Microlattices, Science 334 (2011) 962-965.

[40] A.G. Evans, J.W. Hutchinson, N.A. Fleck, M.F. Ashby, H.N.G. Wadley. The topological design of multifunctional cellular metals, Prog Mater Sci 46 (2001) 309-327. 
[41] A.G. Evans, J.W. Hutchinson, M.F. Ashby. Multifunctionality of cellular metal systems, Prog Mater Sci 43 (1998) 171-221.

[42] B. Sarac, J. Schroers. From brittle to ductile: Density optimization for Zr-BMG cellular structures, Scripta Materialia 68 (2013) 921-924.

[43] B. Sarac, J. Ketkaew, D.O. Popnoe, J. Schroers. Honeycomb Structures of Bulk Metallic Glasses, Advanced Functional Materials 22 (2012) 3161-3169.

[44] W. Chen, Z. Liu, H.M. Robinson, J. Schroers. Flaw tolerance vs. performance: A tradeoff in metallic glass cellular structures, Acta Materialia 73 (2014) 259-274.

[45] E. Sachs, M. Cima, P. Williams, D. Brancazio, J. Cornie. 3-Dimensional Printing - Rapid Tooling and Prototypes Directly from a Cad Model, J Eng Ind-T Asme 114 (1992) 481-488.

[46] X.Y. Zheng, H. Lee, T.H. Weisgraber, M. Shusteff, J. DeOtte, E.B. Duoss, J.D. Kuntz, M.M. Biener, Q. Ge, J.A. Jackson, S.O. Kucheyev, N.X. Fang, C.M. Spadaccini. Ultralight, Ultrastiff Mechanical Metamaterials, Science 344 (2014) 1373-1377.

[47] E.B. Duoss, T.H. Weisgraber, K. Hearon, C. Zhu, W. Small, T.R. Metz, J.J. Vericella, H.D. Barth, J.D. Kuntz, R.S. Maxwell. Three - Dimensional Printing of Elastomeric, Cellular Architectures with Negative Stiffness, Advanced Functional Materials 24 (2014) 4905-4913.

[48] E. Andreassen, B.S. Lazarov, O. Sigmund. Design of manufacturable 3D extremal elastic microstructure, Mech Mater 69 (2014) 1-10.

[49] S. Pauly, L. Lober, R. Petters, M. Stoica, S. Scudino, U. Kuhn, J. Eckert. Processing metallic glasses by selective laser melting, Materials Today 16 (2013) 37-41.

[50] W. Chen, Z. Liu, J. Schroers. Joining of bulk metallic glasses in air, Acta Materialia 62 (2014) 49-57.

[51] Z. Liu, J. SCHROERS. General nanomoulding with bulk metallic glasses, Nanotechnology 26 (2015) 
145301-145309.

[52] G. Kumar, D. Rector, R.D. Conner, J. Schroers. Embrittlement of Zr-based bulk metallic glasses, Acta Materialia 57 (2009) 3572-3583.

[53] G. KUMAR, P. Neibecker, Y.H. Liu, J. SCHROERS. Critical fictive temperature for plasticity in metallic glasses, Nat Commun 4 (2013) 1-6.

[54] T. Wada, A. Inoue, A.L. Greer. Enhancement of room-temperature plasticity in a bulk metallic glass by finely dispersed porosity, Applied Physics Letters 86 (2005) 251907.

[55] A.H. Brothers, D.C. Dunand. Plasticity and damage in cellular amorphous metals, Acta Materialia 53 (2005) 4427-4440.

[56] A.H. Brothers, D.C. Dunand. Amorphous metal foams, Scripta Materialia 54 (2006) 513-520.

[57] A.H. Brothers, D.C. Dunand. Ductile bulk metallic glass foams, Advanced Materials 17 (2005) 484-486.

[58] M.D. Demetriou, J.C. Hanan, C. Veazey, M. Di Michiel, N. Lenoir, E. Ustundag, W.L. Johnson. Yielding of metallic glass foam by percolation of an elastic buckling instability, Advanced Materials 19 (2007) 1957-1962.

[59] L.J. Gibson, M.F. Ashby. Cellular solids: structure and properties. 2 ed., Cambridge University Press, 1999.

[60] R.T. Ott, F. Sansoz, J.F. Molinari, J. Almer, K.T. Ramesh, T.C. Hufnagel. Micromechanics of deformation of metallic-glass-matrix composites from in situ synchrotron strain measurements and finite element modeling, Acta Materialia 53 (2005) 1883-1893.

[61] G. Duan, A. Wiest, M.L. Lind, J. Li, W.K. Rhim, W.L. Johnson. Bulk metallic glass with benchmark thermoplastic processability, Advanced Materials 19 (2007) 4272-4275.

[62] A.E. Simone, L.J. Gibson. Effects of solid distribution on the stiffness and strength of metallic foams, Acta Materialia 46 (1998) 2139-2150.

[63] J.T. Beals, M.S. Thompson. Density gradient effects on aluminium foam compression behaviour, J Mater 
Sci 32 (1997) 3595-3600.

[64] A.E. Simone, L.J. Gibson. Aluminum foams produced by liquid-state processes, Acta Materialia 46 (1998)

3109-3123.

\section{Figure captions}

Fig. 1 Fabrication of 3D BMG structures: a) BMG sheets obtained by thermoplastic hot rolling. b) Thermoplastic based compression molding is used to fabricate corrugated BMG sheets. c) TPF-based joining of corrugated BMG sheets under compression. d) 3D BMG structure after removal of support. e) Typical honeycomb-like BMG structure, with dimensions approximately $3 \mathrm{~cm} 3 \mathrm{~cm} 2 \mathrm{~cm}$. f) Honeycomb-like hierarchical BMG structure.

Fig. 2 Visualization of the surface oxide layer cross-section under scanning electron microscopy. Such cross-section was achieved by tension of a BMG sheet after TPF.

Fig. 3 Microstructural characterizations by DSC (a) and XRD (b) of the BMG sheets after thermoplastic rolling. The almost same crystallization enthalpy for as-cast BMG of $\Delta H_{\text {As-cast }}=$ 127.2 J/g and as-rolled $\mathrm{BMG}$ of $\Delta H_{\mathrm{As} \text {-rolled }}=126.7 \mathrm{~J} / \mathrm{g}$, respectively suggested a fully amorphous structure after rolling (a), which was further verified by the XRD pattern that demonstrates amorphous halo-like diffraction pattern (b).

Fig. 4 Quasi-static compression of a 3D BMG honeycomb-like structure with density of 0.39 $\mathrm{g} / \mathrm{cm}^{3}$ (or relative density of $\rho / \rho_{\mathrm{s}}=0.073$ ). The stress-strain curve contains high elasticity $(\sim 15 \%)$, plastic yielding, which is terminated by densification.

Fig. 5 a) A typical honeycomb unit cell after compression to $90 \%$ strain. b)-c) Severely distorted deformations occur without crack formation near the roots of the beams (A and B in 
a)). d)-e) Subsequent breaking of a joint reveals vein-patterns in both of the break surfaces, indicating metallic chemical bonding in these regions.

Fig. 6 Super-elasticity in a 3D honeycomb-like BMG structure with relative density $\rho / \rho_{\mathrm{s}}=$ 0.031. The entire structure can be fully recovered at a loading $35 \%$ strain. The residual strain is below $2 \%$, even when the loading strain is increased to $40 \%$.

Fig. 7 a) Honeycomb architecture under uni-axial compression. b) Bending-dominated elastic deformation.

Fig. 8 Maximum elasticity and maximum stored elastic strain energy for a regular honeycomb structure calculated according to Eqs. (1)-(4). The experimental results for 3D honeycomb-like structures made from $\mathrm{Zr}_{35} \mathrm{Ti}_{30} \mathrm{Cu}_{8.25} \mathrm{Be}_{26.75}$ agree with the theoretical results.

Fig. 9 Comparison of mechanical responses of cellular structures from experiments with FEA.

a) Stress-strain curves for honeycomb-like structures made from $\mathrm{Zr}_{35} \mathrm{Ti}_{30} \mathrm{Cu}_{8.25} \mathrm{Be}_{26.75}$, where the dot-dashed lines are from experiments and the solid-lines are from FEA. b) The peak stress calculated from FEA sets the upper bounds for experimental results. Similar behavior was reported before for aluminum foams [54-56]. However, for the same relative density, 3D BMG structures are superior compared to aluminum cellular structures.

Fig. 10 Deformed shape and stress contours for relative densities of a),d) 0.06 and b),e) 0.11 .

c) Zoomed in view of finite element mesh for a), d).

\section{Table captions}

Table 1. Comparing processing methods for metallic glass architecture structures.

Table 2. Sidewall length $L$ and wall thickness $t$ of the analyzed perfect hexagonal honeycombs. 


\section{Figures}

(a) MG sheet
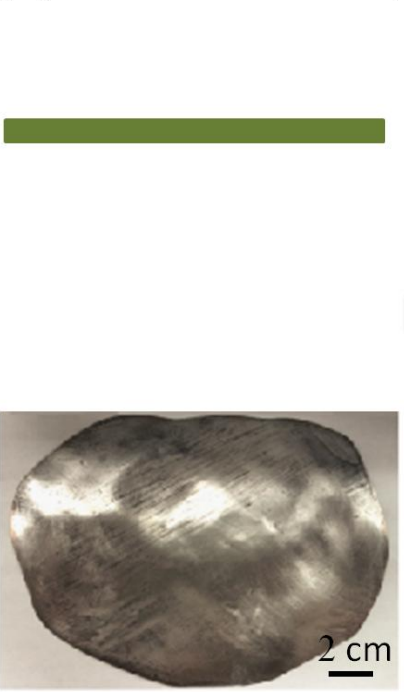

(e) Honeycomb MG structure

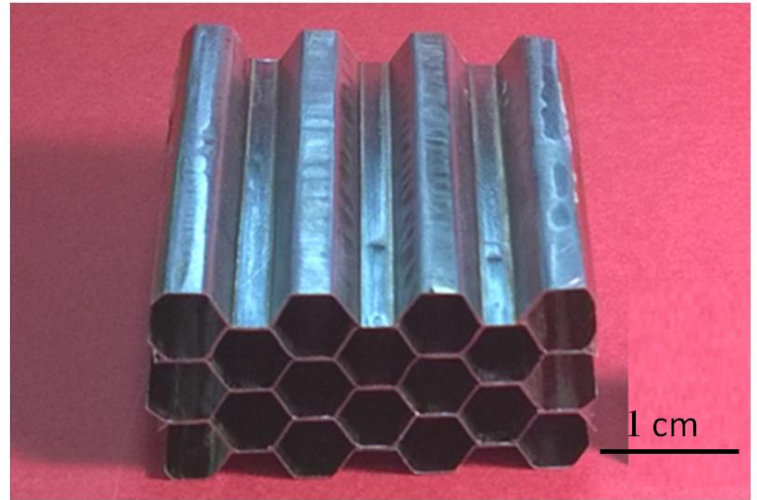

(b) Patterning at perforating

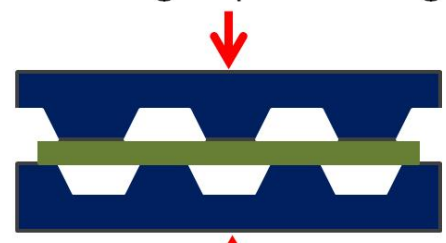

$\uparrow_{F}$
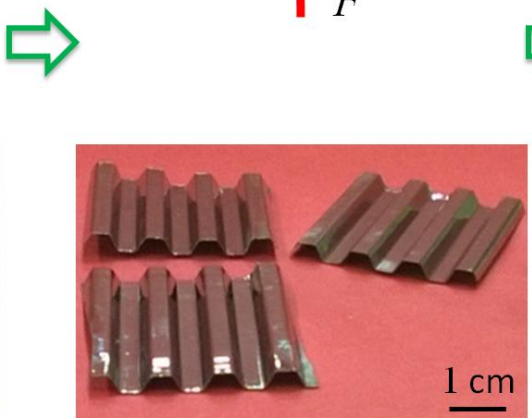

(c) Joining

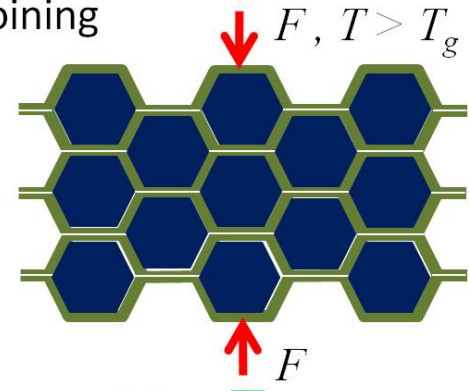

(d) Demoulding

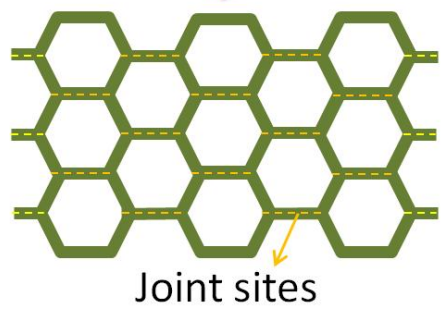

(f) Honeycomb MG hierarchical structure

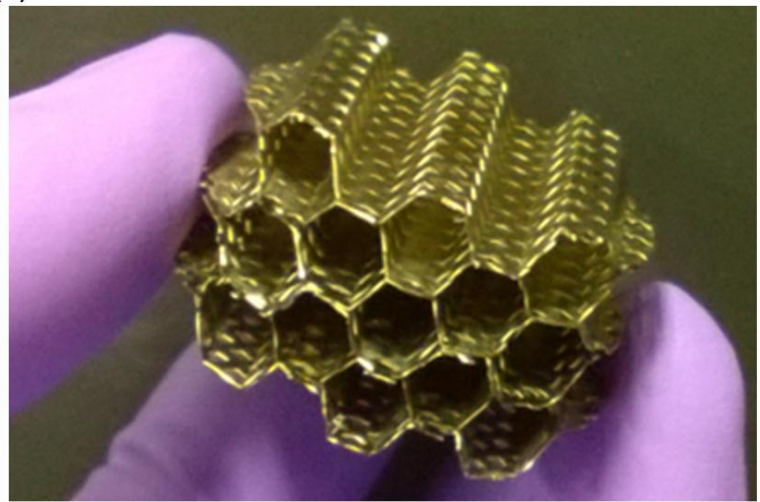

Fig. 1 Liu $\mathbf{Z}$ et al. Fabrication of 3DBMG structures: a) BMG sheets obtained by thermoplastic hot rolling. b) Thermoplastic based compression molding is used to fabricate corrugated BMG sheets. c) TPF-based joining of corrugated BMG sheets under compression. d) 3D BMG structure after removal of support. e) Typical honeycomb-like BMG structure, with dimensions approximately $3 \mathrm{~cm} \times 3 \times \mathrm{cm} \times 2$ cm. f) Honeycomb-like hierarchical BMG structure. 


\section{$500 \mathrm{~nm}$}

Fig. 2 Liu $\mathbf{Z}$ et al. Visualization of the surface oxide layer cross-section under scanning electron microscopy. Such cross-section was achieved by tension of a BMG sheet after TPF.
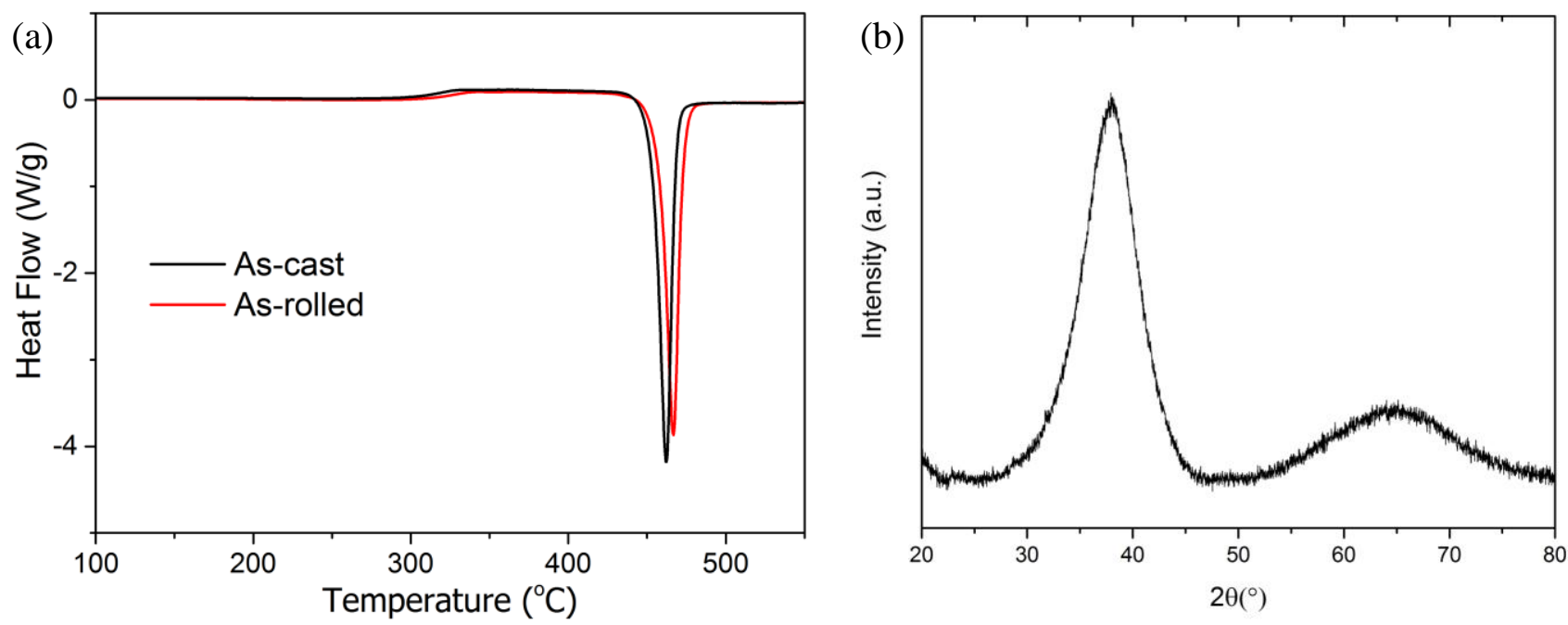

Fig. 3 Liu Z et al. Microstructural characterizations by DSC (a) and XRD (b) of the BMG sheets after thermoplastic rolling. The almost same crystallization enthalpy for as-cast BMG of $\Delta H_{\text {As-cast }}=127.2 \mathrm{~J} / \mathrm{g}$ and as-rolled $\mathrm{BMG}$ of $\Delta H_{\mathrm{As} \text {-rolled }}=126.7 \mathrm{~J} / \mathrm{g}$, respectively suggested a fully amorphous structure after rolling (a), which was further verified by the XRD pattern that demonstrates amorphous halo-like diffraction pattern (b). 


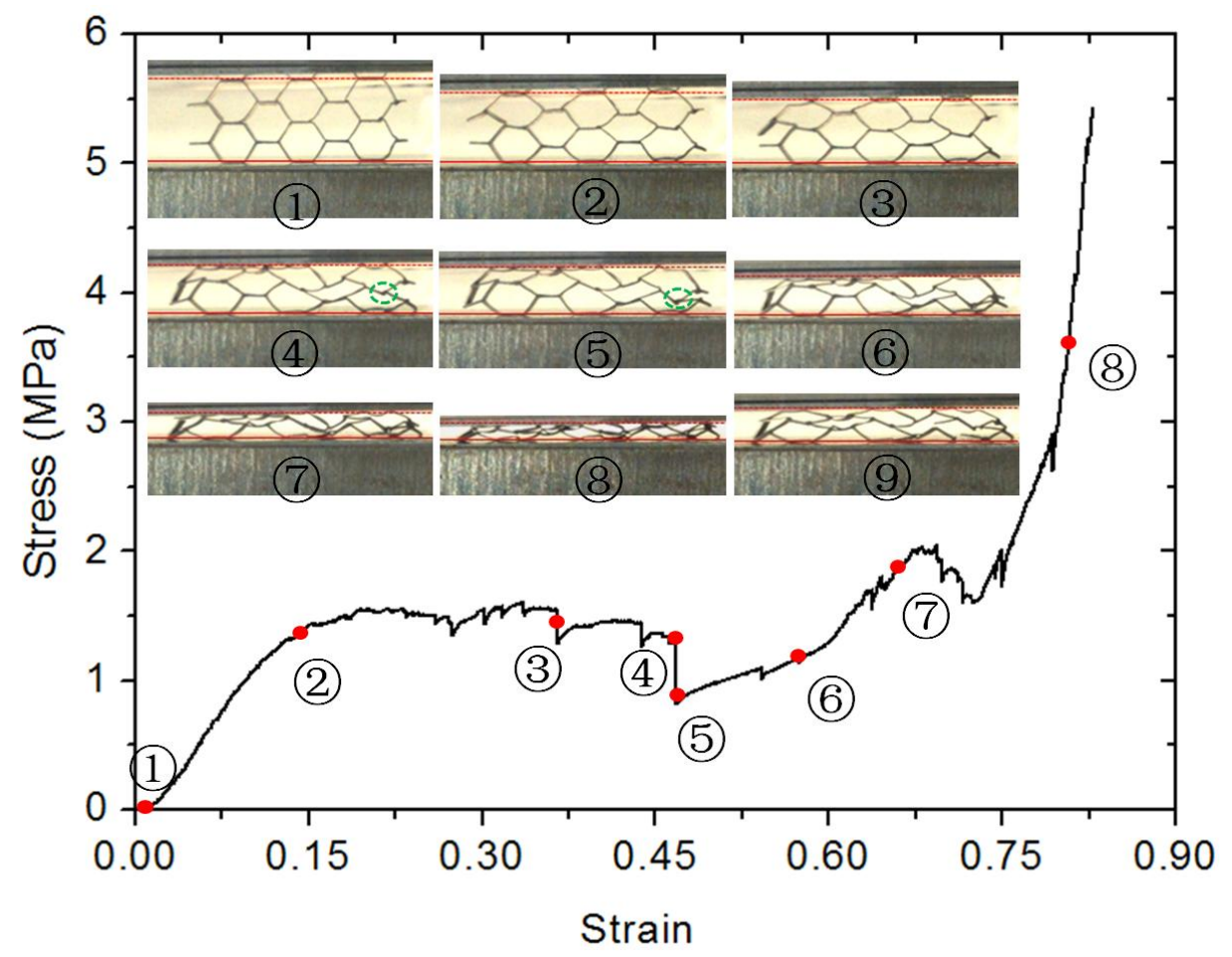

Fig. 4 Liu Z et al. Quasi-static compression of a 3DBMG honeycomb-like structure with density of 0.39 $\mathrm{g} / \mathrm{cm}^{3}$ (or relative density of $\rho / \rho_{\mathrm{s}}=0.073$ ). The stress-strain curve contains high elasticity $(\sim 15 \%)$, plastic yielding, which is terminated by densification.

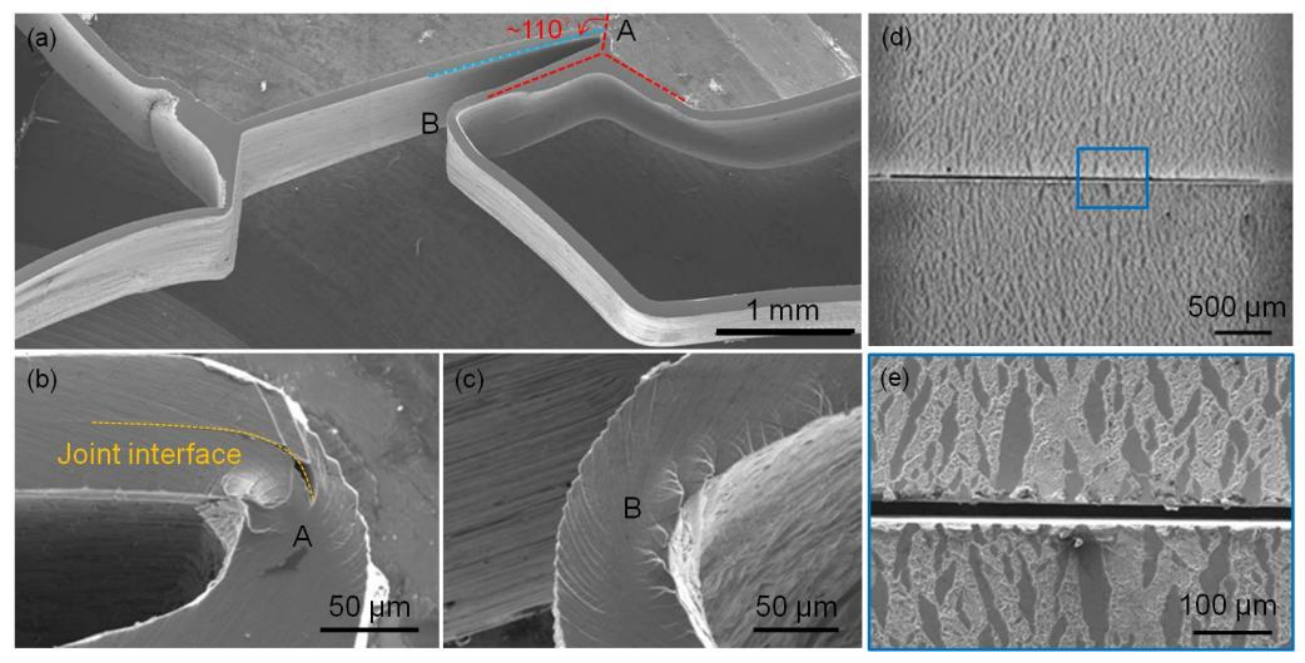

Fig. 5 Liu Z et al. a) A typical honeycomb unit cell after compression to $90 \%$ strain. b)-c) Severely distorted deformations occur without crack formation near the roots of the beams (A and B in a)). d)-e) Subsequent breaking of a joint reveals vein-patterns in both of the break surfaces, indicating metallic chemical bonding in these regions. 


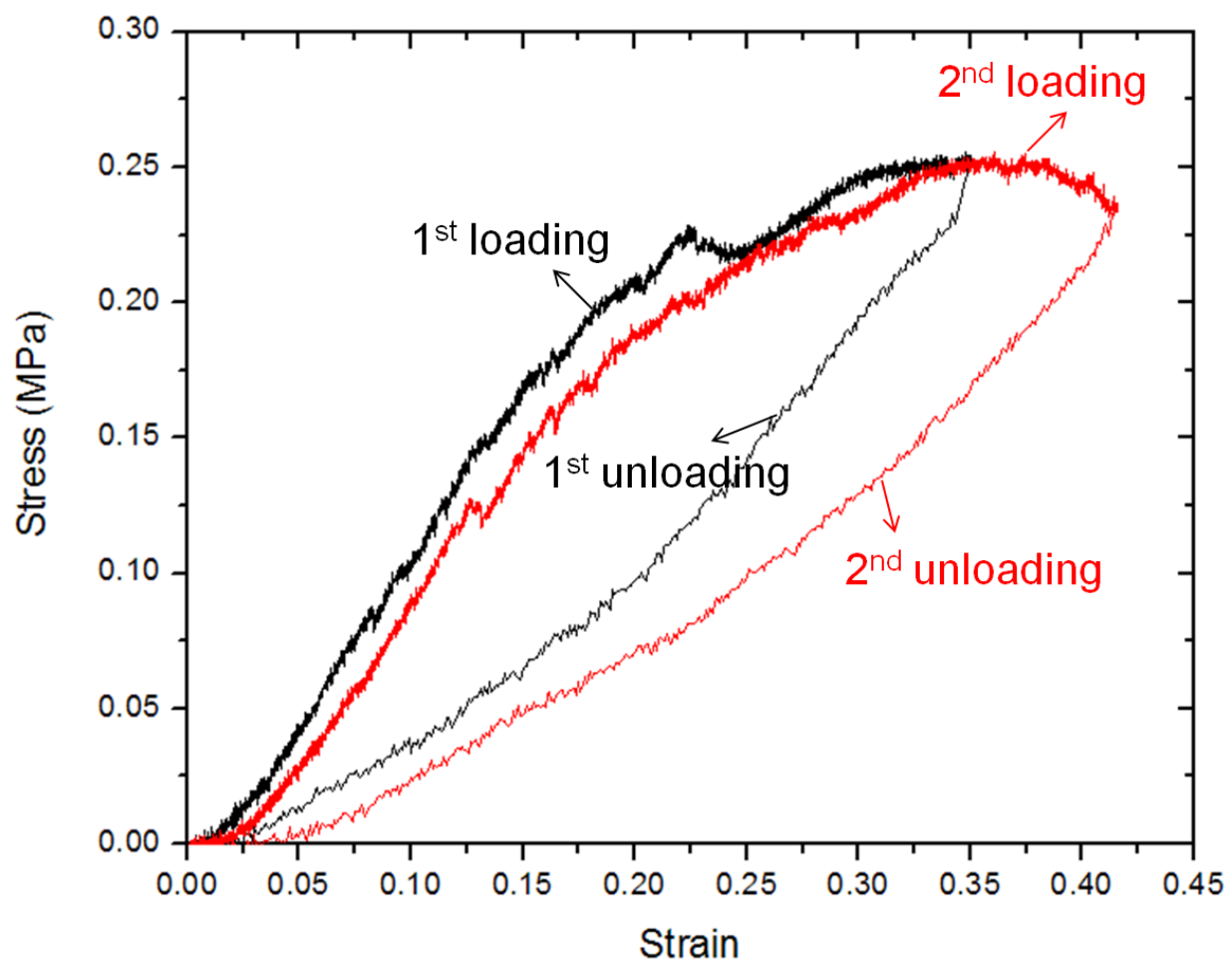

Fig. 6 Liu Z et al. Super-elasticity in a 3D honeycomb-like BMG structure with relative density $\rho / \rho_{\mathrm{s}}=$ 0.031. The entire structure can be fully recovered at a loading $35 \%$ strain. The residual strain is below $2 \%$, even when the loading strain is increased to $40 \%$.

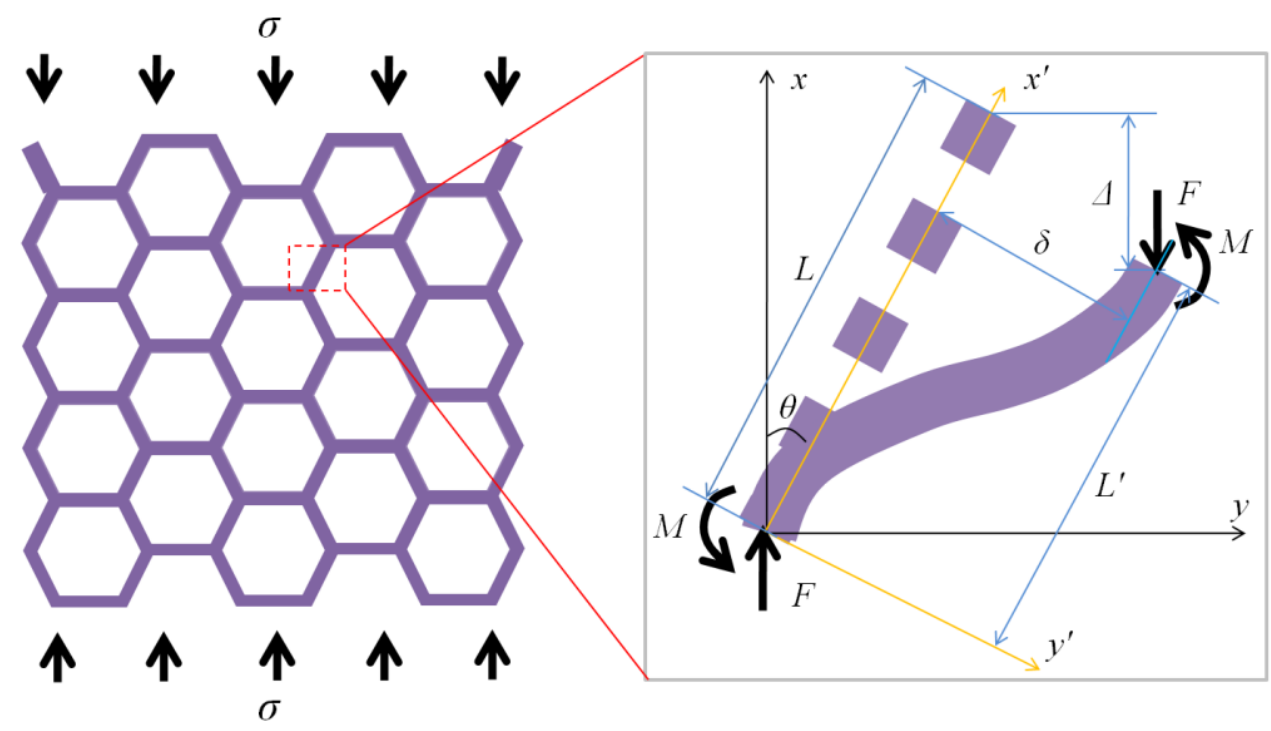

(a)

(b)

Fig. 7 Liu $\mathbf{Z}$ et al. a) Honeycomb architecture under uni-axial compression. b) Bending-dominated elastic deformation. 
(a)

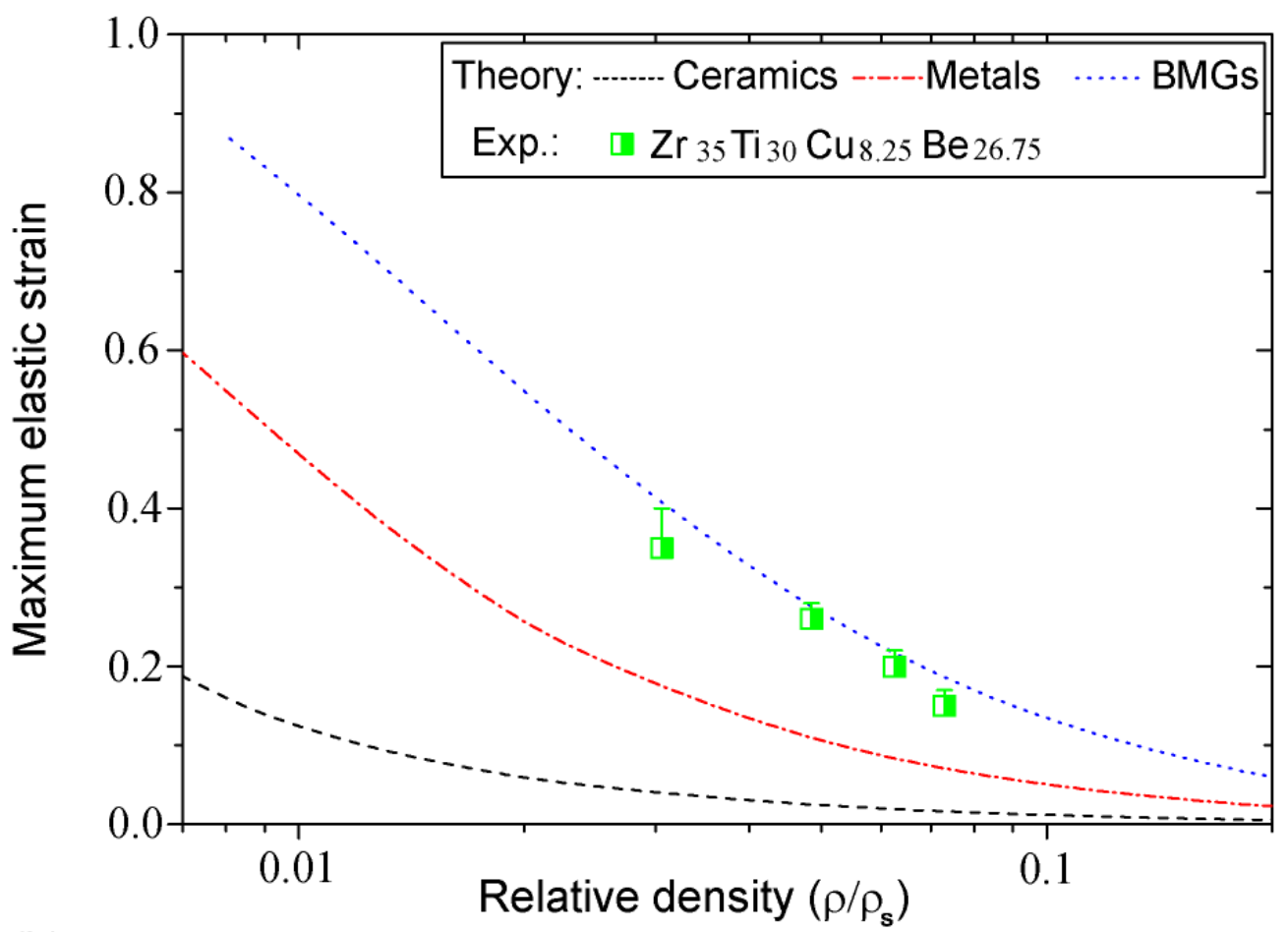

(b)

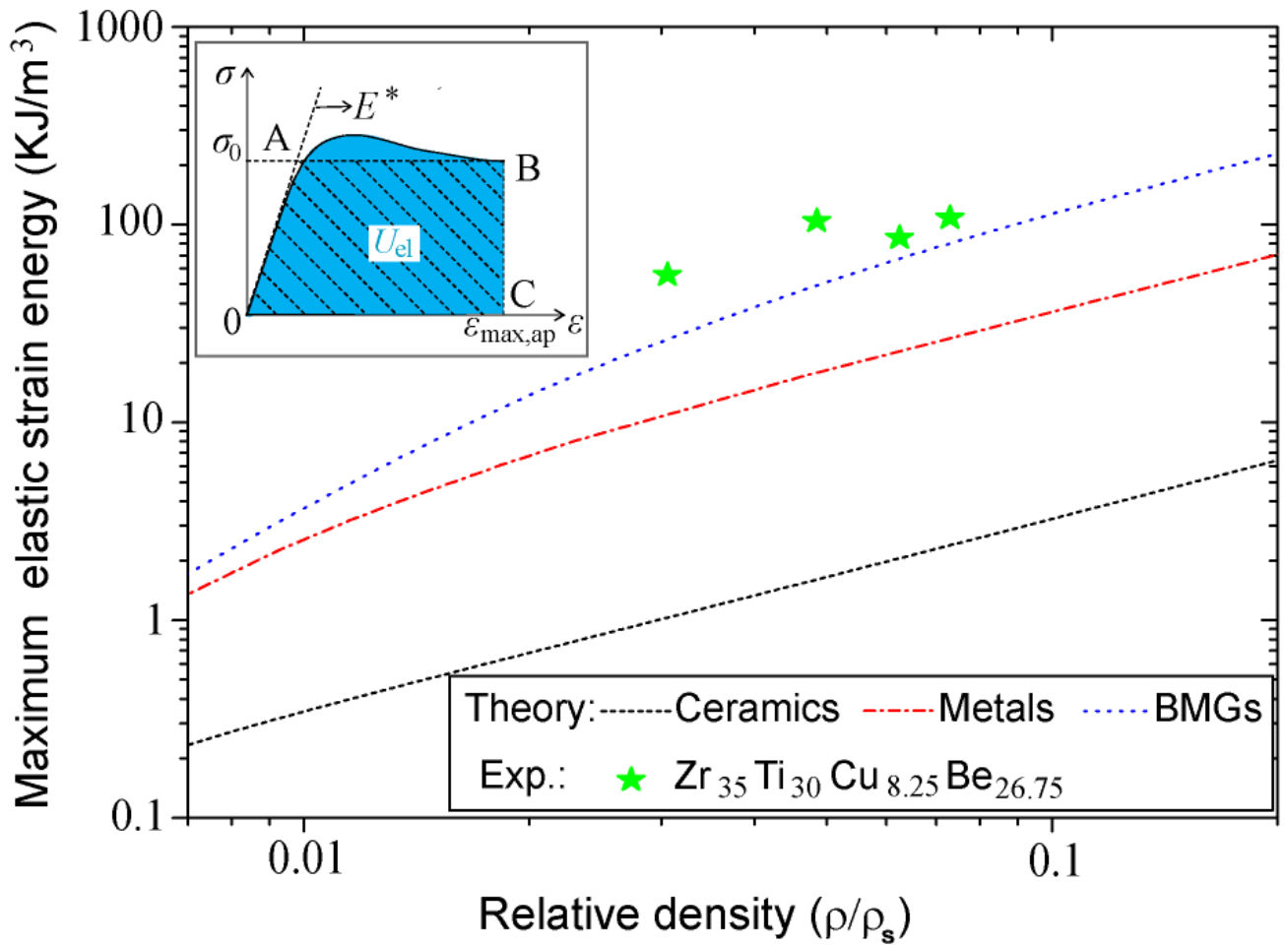

Fig. 8 Liu $\mathrm{Z}$ et al. Maximum elasticity and maximum stored elastic strain energy for a regular honeycomb structure calculated according to Eqs. (1)-(4). The experimental results for 3D honeycomblike structures made from $\mathrm{Zr}_{35} \mathrm{Ti}_{30} \mathrm{Cu}_{8.25} \mathrm{Be}_{26.75}$ agree with the theoretical results. 

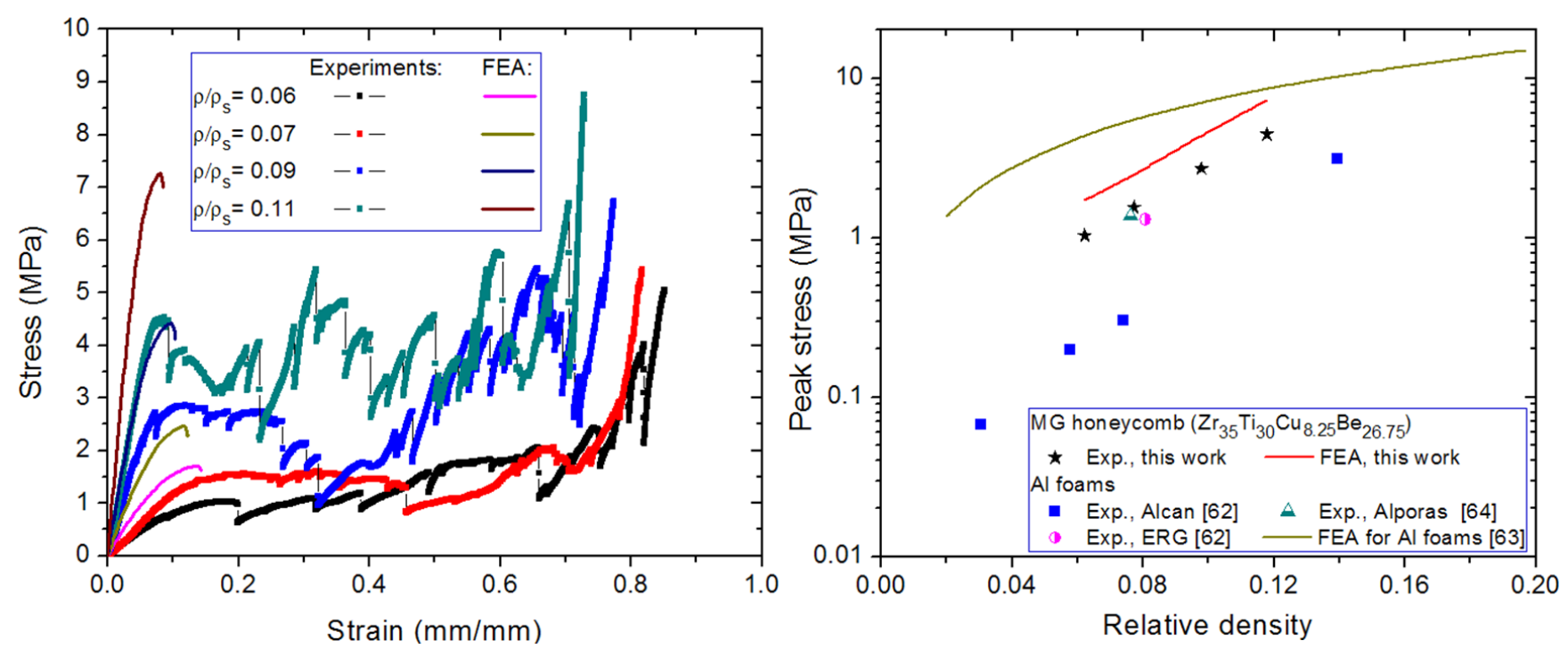

Fig. 9 Liu Z et al. Comparison of mechanical responses of cellular structures from experiments with FEA. a) Stress-strain curves for honeycomb-like structures made from $\mathrm{Zr}_{35} \mathrm{Ti}_{30} \mathrm{Cu}_{8.25} \mathrm{Be}_{26.75}$, where the dot-dashed lines are from experiments and the solid-lines are from FEA. b) The peak stress calculated from FEA sets the upper bounds for experimental results. Similar behavior was reported before for aluminum foams [62-64]. However, for the same relative density, 3D BMG structures are superior compared to aluminum cellular structures. 


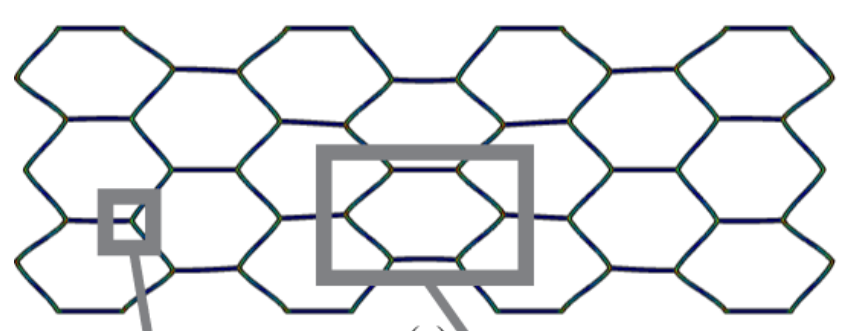

(a)

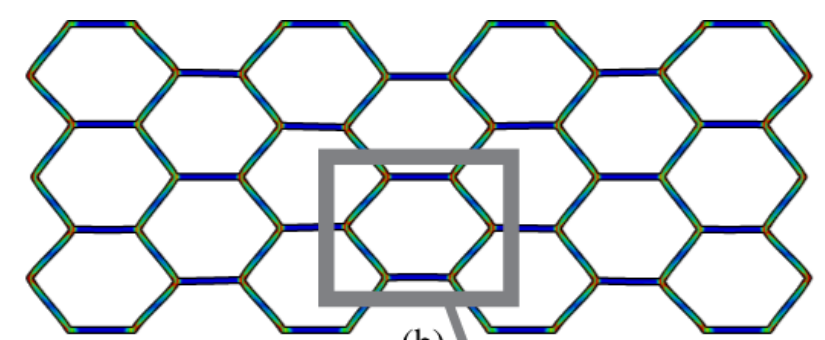

(b)

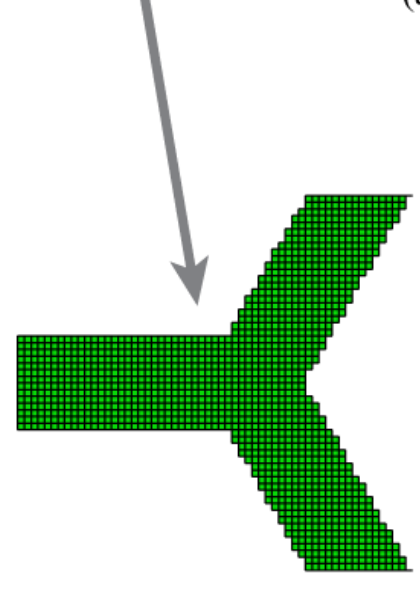

(c)

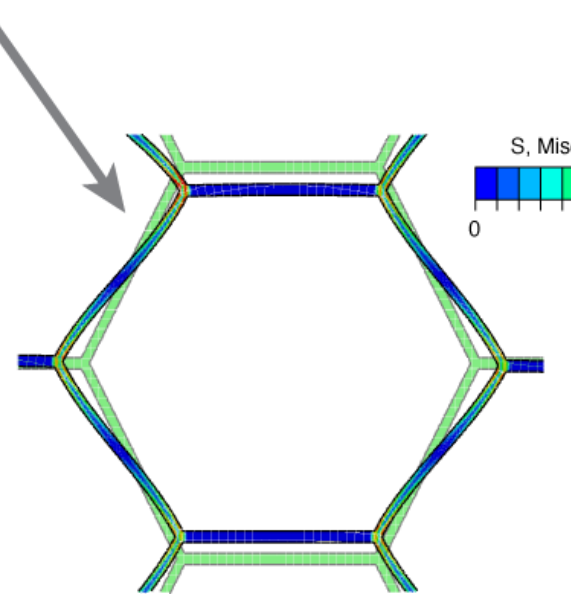

(d)

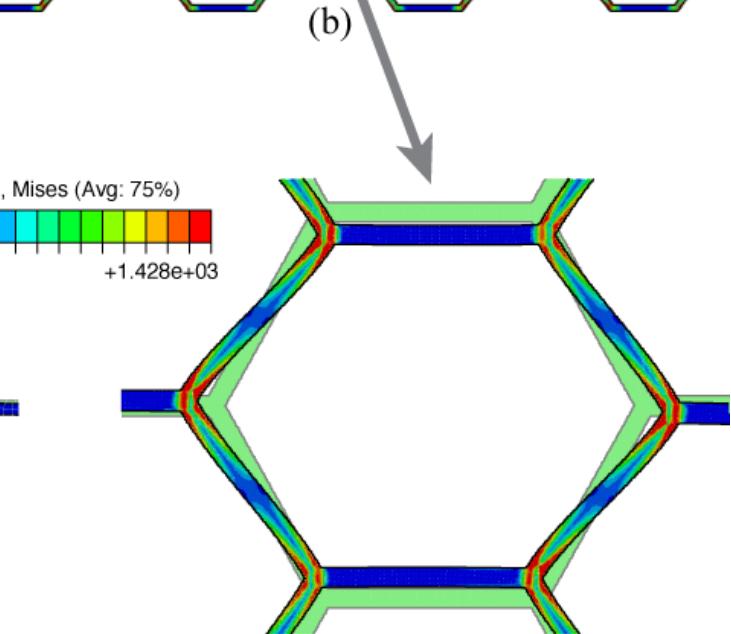

(e)

Fig. 10 Liu Z et al. Deformed shape and stress contours for relative densities of a),d) 0.06 and b),e)

0.11. c) Zoomed in view of finite element mesh for a),d). 


\section{Tables}

Table 1. Comparing processing methods for metallic glass architecture structures

\begin{tabular}{|c|c|c|c|c|c|}
\hline Methods & $\begin{array}{c}\text { Size } \\
{[\mathrm{mm}]}\end{array}$ & $\begin{array}{c}\text { Porosity } \\
{[\%]}\end{array}$ & Controllability & $\begin{array}{l}\text { Hierarchical } \\
\text { features }\end{array}$ & Costs \\
\hline
\end{tabular}

\begin{tabular}{|c|c|c|c|c|c|c|}
\hline $\begin{array}{l}\text { Foaming during } \\
\text { casting }^{\text {a) }}\end{array}$ & $1-10$ & $10-85$ & Low & No & Medium & $\begin{array}{l}\text { Limited to one } \\
\text { dimension to } \\
\text { prevent } \\
\text { crystallization }\end{array}$ \\
\hline $\begin{array}{l}\text { Thermoplastic } \\
\text { forming and } \mathrm{Si} \\
\text { lithography }\end{array}$ & $\sim 1$ & $5-95$ & Very good & Yes & High & $\begin{array}{l}\text { General challenging } \\
\text { to avoid microvoids } \\
\text { and microcracks }\end{array}$ \\
\hline $\begin{array}{l}\text { Template- } \\
\text { assisted } \\
\text { electroless } \\
\text { plating }^{c}\end{array}$ & 10 & 99.3- 99.9 & Excellent & Yes & $\begin{array}{l}\text { Very } \\
\text { high }\end{array}$ & $\begin{array}{l}\text { Difficult to scale- } \\
\text { up and limited to } \\
\text { ultrahigh porosity }\end{array}$ \\
\hline 3D printing ${ }^{d)}$ & $>1$ & $10-99$ & Very good & Yes & High & Limited to $2 \mathrm{D}$ \\
\hline $\begin{array}{l}\text { Thermoplastic } \\
\text { forming and } \\
\text { parallel joining }\end{array}$ & $>10$ & $85-99$ & Very good & Yes & Low & Scale-up possible \\
\hline
\end{tabular}

Table 2. Side length $L$ and thickness $t$ of the analyzed perfect hexagonal honeycombs.

\begin{tabular}{ccccc} 
Sample: & 0.06 & 0.07 & 0.09 & 0.11 \\
\hline $\begin{array}{c}\left(\rho / \rho_{\mathrm{s}}\right)- \\
\text { theoretical }\end{array}$ & 0.058 & 0.073 & 0.094 & 0.109 \\
\hline $\begin{array}{c}\left(\rho / \rho_{\mathrm{s}}\right)- \\
\text { numerical }\end{array}$ & 0.058 & 0.070 & 0.090 & 0.109 \\
\hline $\begin{array}{c}L[\mathrm{~mm}] \\
h[\mathrm{~mm}]- \\
\text { theoretical }\end{array}$ & 280 & 205 & 160 & 160 \\
\hline $\begin{array}{c}h[\mathrm{~mm}]- \\
\text { numerical }\end{array}$ & 13.25 & 13 & 13 & 15.30 \\
\hline
\end{tabular}




\section{Graphical Abstract}

A scalable fabrication method for 3DBMG structures by thermoplastic forming and parallel joining is introduced. Experimental characterization and theoretical analysis of 3D BMGs' mechanical behaviors reveal excellent elasticity and elastic energy storability paired with very high energy absorption ability. The combination of BMG properties and the developed versatile fabrication method suggest the possibility to develop a wide range of BMG structures with excellent performance for specific applications.
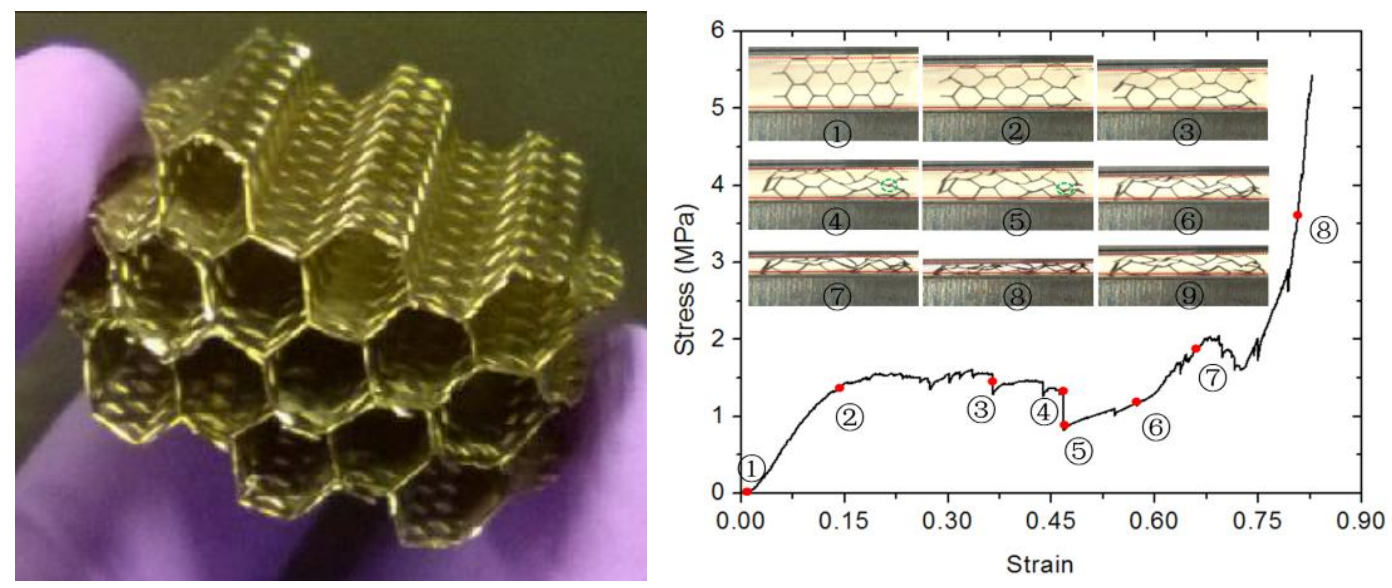